\title{
Avoiding Interference: Adult Attachment and Emotional Processing Biases
}

\author{
Robin S. Edelstein \\ University of Michigan \\ Omri Gillath \\ University of Kansas
}

The present study investigated attachment-related differences in emotional processing biases. Consistent with the proposal that avoidant individuals limit attention to potentially distressing information, attachment avoidance was associated with reductions in emotional Stroop (ES) interference for attachment-related words (e.g., intimate, loss). These biases were strongest among individuals who were currently in a romantic relationship, suggesting that being in a close relationship may activate avoidant defensive strategies. In addition, avoidant attentional biases were attenuated under cognitive load, suggesting that inhibiting attention to attachmentrelated information requires cognitive effort. Finally, avoidance was unrelated to ES performance for emotional, nonattachment-related words, demonstrating the specificity of these attentional biases. The present findings suggest that avoidant individuals can inhibit attention to potentially threatening information, that this ability requires cognitive effort, and that relationship status may be an important moderator of avoidant defensive strategies. The implications of these strategies for emotional functioning and well-being are discussed.

Keywords: attachment; avoidance; emotion; emotional Stroop; attention; personality

$\mathrm{E}$ motional information captures attention. Compared to neutral stimuli, those that are emotional tend to be processed more quickly, extensively, and automatically (e.g., Ohman, Flykt, \& Esteves, 2001; Pratto \& John, 1991). Emotional material is more likely to elicit physiological responses (e.g., Hamann, Ely, Hoffman, \& Kilts, 2002; Lang, Greenwald, Bradley, \& Hamm, 1993) and tends to be recalled more accurately and vividly than neutral material (e.g., Kensinger \& Corkin, 2003; Ochsner, 2000), even after long delays (M. M. Bradley, Greenwald, Petry, \& Lang, 1992; Dolcos, LaBar, \& Cabeza, 2005). This preferential processing of emotional information is thought to reflect an evolutionarily adaptive response to information that is likely to signal environmental threat or reward (Lang, Bradley, \& Cuthbert, 1997).

Yet there is considerable individual variation in the nature and extent of emotional influences on information processing (Hamann \& Canli, 2004). For instance, in both clinical and nonclinical populations, highly anxious individuals tend to have greater difficulty disengaging from emotional stimuli (e.g., B. P. Bradley, Mogg, Falla, \& Hamilton, 1998; Kaspi, McNally, \& Amir, 1995). In contrast, for some individuals, the attentioncapturing power of emotional material may be attenuated, perhaps because the information is not perceived as emotional or because such material has been repeatedly ignored, suppressed, or avoided (e.g., Newman \& McKinney, 2002). That is, some individuals may orient attention away from, rather than toward, emotional

Authors' Note: The first author was supported by a predoctoral fellowship from the National Institute of Mental Health (NIMH Grant T32 MH20006) and a postdoctoral fellowship from NIMH (Grant T32 MH19958). Portions of this research were presented at the 2006 meeting of the Society for Personality and Social Psychology in Palm Springs, California. Correspondence concerning this article should be addressed to Robin Edelstein, Department of Psychology, University of Michigan, 530 Church Street, Ann Arbor, MI 48109; e-mail: redelste @umich.edu.

PSPB, Vol. 34 No. 2, February 2008 171-181

DOI: $10.1177 / 0146167207310024$

(C) 2008 by the Society for Personality and Social Psychology, Inc. 
stimuli. Although considerably less research has examined such biases, there is some evidence for reductions in attention to emotional information among individuals with a repressive coping style (e.g., Broomfield \& Turpin, 2005; Fox, 1993).

In the present research, we investigated the nature of attentional biases among avoidantly attached adults. Avoidant individuals are uncomfortable with closeness and intimacy and rely on a variety of defensive strategies to limit the experience and expression of emotion (for review, see Edelstein \& Shaver, 2004; Fraley, Davis, \& Shaver, 1998). In particular, avoidant individuals are thought to inhibit attention to attachment-related information (e.g., emotional material related to closeness, separation; Bowlby, 1980; Fraley et al., 1998); however, experimental evidence for such attentional restrictions is limited. The present study was therefore designed to examine whether avoidant individuals are particularly skilled at inhibiting attention to attachment-related versus nonattachment-related material. To investigate the efficacy of avoidant defensive strategies, we also examined the extent to which the implementation of these biases requires cognitive resources. Finally, we considered whether being in a close relationship might activate avoidant defensive strategies, that is, whether avoidant attentional biases are most pronounced among individuals in a romantic relationship.

\section{Attachment and Attention to Emotional Information}

Individual differences in adult attachment are generally assessed by a person's placement on two relatively independent dimensions: attachment-related avoidance and anxiety (Fraley \& Waller, 1998). High scores on the avoidance dimension reflect chronic attempts to deactivate or minimize activation of the attachment system (Edelstein \& Shaver, 2004; Fraley et al., 1998). Avoidant individuals typically dislike physical and emotional intimacy (Brennan, Clark, \& Shaver, 1998), suppress displays of emotion (Fraley \& Shaver, 1997; Gross \& John, 2003), and reject close others when under stress (e.g., Edelstein et al., 2004; Gillath et al., 2006).

High levels of attachment anxiety, in contrast, reflect fear of being alone and preoccupation with intimacy and relationship partners. Anxious individuals are hypervigilant to attachment figures and attachmentrelated concerns (e.g., Mikulincer, Gillath, \& Shaver, 2002) and easily overwhelmed by interpersonal stressors (e.g., Gillath, Bunge, Shaver, Wendelken, \& Mikulincer, 2005; Mikulincer, Florian, \& Weller, 1993). Individuals with low scores on both avoidance and anxiety are considered secure and neither suppress nor are overwhelmed by threats to the attachment system (e.g., Mikulincer, Shaver, \& Pereg, 2003).
Deactivating strategies, in particular, have important implications for attentional processes (Bowlby, 1980; Eysenck, 1997). Bowlby (1987) proposed that one way to regulate negative affect is to limit attention to potentially threatening material, a process he termed "defensive exclusion." Such defensive behavior may serve to prevent distress associated with reminders of attachmentrelated loss, rejection, or intimacy (e.g., Weiss, 1982). Although avoidant individuals are thought to rely on this kind of defensive strategy (Fraley et al., 1998), there is very little direct evidence for attentional biases among avoidant adults (but see Kirsh \& Cassidy, 1997, for data suggesting that avoidant children are less attentive to attachment-related information).

There is evidence, however, that avoidant adults have difficulty recalling attachment-related experiences (e.g., Edelstein et al., 2005; Mikulincer \& Orbach, 1995 ) and some indication that these difficulties result from processes occurring when information is initially attended to or encoded (Edelstein, 2006; Fraley, Garner, \& Shaver, 2000). For instance, Fraley et al. (2000) found that avoidant individuals had poor memory for a story about interpersonal loss but that avoidance was unrelated to the rate at which story details were forgotten. Insofar as memory is facilitated by postevent elaboration (e.g., thinking or talking with others about the event; Bahrick, 2000), these findings suggest that avoidant and nonavoidant individuals were equally likely to elaborate or rehearse the story after encoding. Fraley et al. thus proposed that encoding or attentional mechanisms underlie avoidant individuals' memory deficits. However, neither attention to the story nor postencoding rehearsal was assessed directly in this study. Rather, the role of these processes was inferred from the rates at which information was forgotten, and comparable forgetting rates could have been obtained if avoidant participants had difficulty retrieving the information, both immediately following encoding and after a delay. Edelstein and colleagues (2005) similarly found that avoidant memory deficits could not be explained by the extent to which the to-be-remembered emotional experience was discussed with others, again providing suggestive, but not conclusive, evidence for restricted encoding and attention.

In a more direct investigation of attentional processes, Edelstein (2006) examined attachment-related differences in working memory (WM) capacity for information varying in attachment relevance. Individual differences in WM capacity are thought to reflect, at least in part, differences in the ability to sustain attention to task-relevant stimuli (Engle, 2002). Avoidance was associated with lower WM capacity for negative and positive attachmentrelated words (e.g., depend, reject). Avoidant WM deficits were not observed for emotionally neutral words, 
however, or for words that were emotional but not attachment related (e.g., beauty, gossip), suggesting that avoidant individuals selectively restrict attention to attachment-related material (but see Gillath, Giesbrecht, \& Shaver, 2007).

Although these findings provide preliminary evidence both for avoidant attentional biases and for the specificity of those biases, assessments of WM capacity are not necessarily ideal measures of attention (see Miyake \& Shah, 1999). Deficits in WM may reflect not only attentional difficulties but also limitations in storage capacity or retrieval efficiency (e.g., Bayliss, Jerrold, Gunn, \& Baddeley, 2003). Therefore, in the present study, we employed the emotional Stroop (ES) task (Williams, Mathews, \& MacLeod, 1996), a widely used measure of attention to emotional information, and examined the hypothesis that avoidant individuals would limit attention to emotional information depicting attachment-related themes.

In addition, although some research suggests that avoidant defensive strategies can operate fairly effortlessly and without taxing cognitive resources (e.g., Fraley \& Shaver, 1997), there is growing evidence that the efficacy of such strategies is attenuated over time (e.g., Berant, Mikulincer, \& Florian, 2001), in highly stressful situations (e.g., Mikulincer et al., 1993), and when concurrent tasks are imposed (e.g., Mikulincer, Dolev, \& Shaver, 2004). Thus, we also investigated the extent to which avoidant attentional biases require cognitive effort. If avoidant individuals are not concerned with attachmentrelated stimuli, inhibiting attention to them should not be particularly difficult and the imposition of a secondary task should not interfere with their ability to do so. However, if avoidant individuals' lack of attention reflects an effortful inhibitory process, imposing a secondary task should reduce attentional biases.

Theoretically, anxious individuals should be especially attentive to attachment-related information; however, this hypothesis has received only limited empirical support. There is some evidence that anxious adults are vigilant to emotional facial expressions (Fraley, Niedenthal, Marks, Brumbaugh, \& Vicary, 2006) and show heightened cognitive accessibility of attachmentrelated material (e.g., Gillath et al., 2005; Mikulincer et al., 2002; Mikulincer \& Orbach, 1995). However, other findings suggest that anxious individuals are less attentive to threatening material (van Emmichoven, van IJzendoorn, de Ruiter, \& Brosschot, 2003) and that attachment anxiety is unrelated to WM for attachment-related and nonattachment-related information (Edelstein, 2006). These inconsistent findings could be due to reliance on indirect measures of attention, stimuli that are not specifically attachment related, or some combination of these factors. The present study allowed us to reexamine the association between attachment anxiety and attention using a more direct attentional measure and stimuli varying in attachment relevance.

\section{EMOTIONAL PROCESSING BIASES}

\section{Emotional Stroop (ES) Task}

In the ES task (Williams et al., 1996), participants view a series of colored words and are instructed to name the color in which each word is printed. Latency of color naming is thought to reflect the extent to which the semantic meaning of a particular word captures participants' attention, with longer response times indicating greater difficulty disengaging from the word's meaning and therefore greater interference with color naming. Across studies, response latencies are typically longer for negative emotional versus neutral words (e.g., McKenna \& Sharma, 1995; Pratto \& John, 1991) and are sometimes longer for positive emotional versus neutral words (Koven, Heller, Banich, \& Miller, 2003; Segerstrom, 2001), suggesting that attention is devoted to processing the meaning of emotional information, which delays color naming.

Furthermore, findings from numerous studies suggest that interference is heightened for emotional material that reflects an individual's current concerns (Williams et al., 1996). For instance, trait anxiety is associated with longer response latencies for threat-related information (e.g., Fox, Russo, Bowles, \& Dutton, 2001; Mogg et al., 2000), and biases reflecting the preferential processing of positive material have been observed among optimistic individuals (Segerstrom, 2001). In clinical samples, response latencies are generally increased for emotional information that is specific to a particular clinical disorder (e.g., increased interference for combat-related words among combat veterans with posttraumatic stress disorder; Kaspi et al., 1995).

Following this reasoning, reductions in interference should be observed to the extent that individuals are not concerned with particular material or have frequently suppressed, ignored, or avoided that material (e.g., Kelly \& Kahn, 1994). Although this kind of bias, indicating an attenuation of attention to emotional versus neutral information, has not often been investigated, there is some evidence that individuals with a repressive coping style show less ES interference for personally threatening versus neutral material (e.g., Newman \& McKinney, 2002). In the present study, we examined the hypothesis that individuals with an avoidant attachment style would show reductions in ES interference, specifically for emotional information with attachment-related themes. 
We also explored a potential moderator of avoidant attentional biases: the experience of being in a romantic relationship. Attachment-related information (e.g., intimacy, abandonment) should be particularly salient among individuals currently in a relationship. As such, and considering the ES literature just described, individuals in a romantic relationship should show greater ES interference for attachment-related information. However, for avoidant individuals, being in a romantic relationship may be threatening (e.g., to independence, self sufficiency) and therefore likely to activate defensive processes. Thus, we explored the possibility that avoidant attentional biases would be most evident among individuals in a romantic relationship.

In one prior study, van Emmichoven et al. (2003) classified participants as secure or insecure (i.e., anxious or avoidant) based on a narrative measure of parent-child attachment and compared ES latencies for neutral and emotional (but not necessarily attachment-related) stimuli. Insecure individuals showed reductions in ES interference for emotional information compared to secure individuals. Although these findings are consistent with the idea that avoidant individuals can limit attention to emotional information, because data were collapsed across insecure individuals, the independent contributions of attachment-related avoidance and anxiety cannot be determined. More important, because the stimuli used in this study were not explicitly attachment related, the specificity of any observed biases is unclear.

Modified Stroop tasks also have been used to examine attachment-related differences in the cognitive accessibility of attachment figures' names (Mikulincer et al., 2002) and the rebound of previously suppressed thoughts of separation (Mikulincer et al., 2004). However, in these studies, participants were first instructed to recall a painful relationship breakup (Mikulincer et al., 2004) or were subliminally primed with neutral or threatening words before each Stroop trial (Mikulincer et al., 2002). These manipulations make it difficult to evaluate the contribution of selective attention per se to differences in response time. Rather, in this context, Mikulincer and colleagues $(2002,2004)$ argue that increased interference reflects heightened cognitive accessibility of a particular construct due to the prime or the experimental manipulation. Moreover, although these studies included explicitly attachment-related stimuli, they did not include comparison stimuli that varied in both attachment relevance and emotional valence. Finally, the stimuli used in these studies were not equated for important lexical properties (e.g., word frequency) that vary between emotional and neutral words and that are associated with response latencies in the ES task (Larsen, Mercer, \& Balota, 2006), further obscuring any inferences that could be made about attentional processes.
Cognitive accessibility of attachment-related constructs (e.g., words related to closeness and distance) also has been assessed using lexical decision (LD) tasks in which participants judge whether a presented stimulus is a word (e.g., Gillath et al., 2006; Mikulincer, Birnbaum, Woddis, \& Nachmias, 2000). LD tasks are not sensitive measures of emotional-processing biases, however, particularly those involving inhibition of attention: There is no competition between responses as in the ES task (i.e., between the semantic meaning of the word and its printed color) and there is some inconsistency in the literature regarding whether and in what direction emotion influences $\mathrm{LD}$ response latencies (e.g., Eysenck, 1992; MacKay et al., 2004).

Thus, in the present study, we used the ES task to investigate whether avoidant individuals limit attention to emotional stimuli with attachment-related themes (e.g., intimacy, rejection) and whether these attentional biases would be stronger among avoidant individuals who were in a romantic relationship. Emotional and neutral nonattachment-related stimuli were included to examine the specificity of any attentional biases. We also assessed whether such biases require cognitive effort by having half of the participants complete the task while under a cognitive load.

\section{METHOD}

\section{Participants}

Participants were 189 undergraduate students $(57 \%$ men; $M$ age $=19.56, S D=1.78)$. Forty-seven percent of participants were Caucasian, 33\% were Asian American, $11 \%$ were Hispanic, and $9 \%$ were of other or mixed ethnicities. Fifty percent of participants $(n=94)$ indicated that they were currently in a romantic relationship. All participants were fluent English speakers; they were recruited from the department subject pool and received course credit for their participation.

\section{Materials}

Adult attachment. The Experiences in Close Relationships Inventory (ECR; Brennan et al., 1998) was used to assess individual differences in adult attachment. The ECR attachment avoidance subscale $(\alpha=$ .93) reflects an individual's discomfort with closeness. The attachment anxiety subscale $(\alpha=.93)$ reflects an individual's concern about abandonment. Sample items include "I don't feel comfortable opening up to romantic partners" (avoidance) and "I often worry that my partner doesn't really love me" (anxiety). Participants rate the extent to which they agree with each statement 
using a scale ranging from 1 (disagree strongly) to 7 (agree strongly).

ES task. In this task, a series of words is presented on a computer screen in one of four colors (blue, green, yellow, or red). Participants are instructed to indicate, as quickly as possible, the color of each word by pressing the corresponding key on a response box.

Participants first completed a practice session that included 45 neutral words not included in any of the other word lists. After the practice session, words were presented in two 160-word blocks. One block contained positive and negative attachment-related words and the other block contained positive and negative emotional (but nonattachment-related) words. Neutral words were randomly presented within each block. Thus, participants completed 320 trials in total, including 160 neutral trials and 40 trials of each of the other four word types (i.e., positive and negative emotional words, positive and negative attachment-related words; see the appendix for sample words). The order of the blocks was counterbalanced and the order of words within each block was randomized. Every word appeared once in each one of the four colors. The ES task was run on a Pentium IBM-PC with a 15 -in. SVGA color monitor and was programmed using Superlab software (Christopher, 2001).

All words in the ES task were previously rated for emotional valence on a scale ranging from 1 (very negative) to 5 (very positive) and attachment relevance on a scale ranging from 1 (not at all attachment related) to 5 (very attachment related). Attachment relevance ratings were provided by advanced graduate students and faculty with extensive background in attachment theory $(n=2-5$ raters per word, $\alpha=.92-.96)$; emotional valence ratings were provided by undergraduate students $(n=46-65$ raters per word; $\alpha=.99)$.

The selected attachment-related words received significantly higher ratings on attachment relevance $(M=4.54$, $S D=0.49)$ compared to the emotional $(M=1.71, S D=$ $0.63)$ and neutral words $(M=1.21, S D=0.49), F(2,77)$ $=274.06, p<.001$; attachment relevance did not differ between the positive $(M=4.63, S D=0.43)$ and negative attachment-related words $(M=4.45, S D=0.56), t(18)=$ $.77, p=.45$. Ratings of emotional valence were also significantly different for the neutral $(M=3.18, S D=0.25)$ versus attachment-related and emotional words, $F(4,75)$ $=229.84, p<.001$, but comparable for positive emotional $(M=4.32, S D=0.22)$ and positive attachment-related words $(M=4.33, S D=0.47)$ and negative emotional $(M$ $=1.56, S D=0.37)$ and negative attachment-related words $(M=1.51, S D=0.18), t s(18)<.98, p s>.41$.

Across word type, words were equated for length, number of syllables, frequency, and concreteness, Fs $<1.09$, ps $>.37$. This information was obtained from the University of South Florida word association, rhyme, and word fragment norms (Nelson, McEvoy, \& Schreiber, 1998) and from the MRC Psycholinguistic Database (Wilson, 1988).

Cognitive load. Participants were randomly assigned to remember either a 1-digit number (low-load condition) or a 7-digit number (high-load condition) while completing the ES task. To ensure compliance with this task, participants were asked to say the designated number aloud at several points during the ES.

\section{Procedure}

Participants completed the ECR online, prior to the experiment, as part of a larger battery of personality measures. Participants could complete these measures at home or in on-campus facilities as long as the measures were completed prior to enrolling in our study. We did not collect information on the delay between completing these questionnaires and participation in our study. Participants came to the laboratory to complete the ES task and were tested individually.

\section{RESULTS}

Descriptive statistics for the study variables are presented in Table 1; zero-order correlations among these variables are presented in Table $2 .{ }^{1}$ Stroop reaction times (RTs) from trials in which participants made errors were deleted and, to reduce skewness of the data, remaining RTs were log-transformed (Ratcliff, 1993). For ease of interpretation, however, all means are reported here in milliseconds rather than transformed values. (Results were virtually identical using the untransformed values.)

ES scores were created for use in subsequent analyses by subtracting the average neutral RT from the average RT for each of the other four word types (i.e., positive and negative emotional words, positive and negative attachment-related words). Larger ES scores therefore reflect greater color-naming interference compared to neutral words. ${ }^{2}$ Gender and block order were unrelated to ES scores (although gender was related to raw RTs; see Table 2) and the effects reported below were unchanged when these variables were included in the analyses, thus neither is considered further. However, because relationship status (i.e., whether participants reported being in a romantic relationship) was associated with avoidance and anxiety scores, and preliminary analyses indicated that this variable moderated the relation between the attachment dimensions and ES scores, this variable was included in subsequent analyses. 
TABLE 1: Descriptive Statistics for Study Variables

\begin{tabular}{lrr}
\hline & M & SD \\
\hline Attachment avoidance & 2.96 & 1.12 \\
Attachment anxiety & 3.69 & 1.25 \\
RT: Attachment words & 696.60 & 89.33 \\
RT: Positive attachment words & 698.36 & 94.55 \\
RT: Negative attachment words & 694.74 & 93.68 \\
RT: Emotional words & 702.68 & 101.80 \\
RT: Positive emotional words & 700.76 & 106.65 \\
RT: Negative emotional words & 704.65 & 102.59 \\
RT: Neutral words & 695.82 & 89.34 \\
Attachment ES score & 0.78 & 40.08 \\
Positive attachment ES score & 2.54 & 56.95 \\
Negative attachment ES score & -1.08 & 41.65 \\
Emotional ES score & 6.85 & 40.05 \\
Positive emotion ES score & 4.94 & 45.69 \\
Negative emotion ES score & 8.82 & 47.97
\end{tabular}

NOTE: Emotional Stroop (ES) scores were computed by subtracting average neutral reaction times (RTs) from the average RT for each of the other word types. Larger scores reflect greater interference compared to neutral words. $N=189$.

The PROC MIXED procedure of SAS (Version 9.1), which can accommodate continuous predictor variables in a repeated-measures design, was used to examine attachment-related differences in ES performance. This analysis included two within-subject factors-word type (emotional vs. attachment-related words) and emotional valence (positive vs. negative) - and two betweensubject factors-cognitive-load condition (low vs. high load) and relationship status (single vs. in a relationship). Attachment avoidance and anxiety scores were entered as continuous covariates. All interactions were simultaneously tested and continuous variables were centered prior to analysis.

The PROC MIXED analysis revealed a main effect of attachment avoidance, $F(1,173)=4.89, p<.05$; a twoway interaction between avoidance and relationship status, $F(1,173)=4.97, p<.05$; and a three-way interaction between avoidance, word type, and cognitive load, $F(1,173)=9.15, p<.01$. These effects were all qualified by a four-way interaction between avoidance, word type, cognitive load, and relationship status, $F(1$, $173)=6.20, p<.05$.

To deconstruct this four-way interaction, separate regression analyses were conducted predicting attachmentrelated and emotional ES scores (collapsed across positive and negative words for each word type given that no interactions with word valence were obtained). Results from these analyses revealed that the three-way interaction between avoidance, relationship status, and cognitive load was significant for the attachment-related words $(\beta=.25, p<.01)$ but not for the emotional words $(\beta=-.01, p=.94)$. To further probe the significant three-way interaction, we plotted the relation between avoidance and attachment-related ES scores for individuals 1 standard deviation above and below the mean of avoidance (Aiken \& West, 1991). Separate regression lines were plotted for participants in the low- and high-cognitive load conditions and for those who were and were not currently in a relationship. The graphical depictions of these interactions are shown in Figures 1 and 2. ${ }^{3}$

As depicted in Figure 1, for individuals currently in a relationship, avoidance was negatively associated with attachment-related ES scores in the low-cognitive load condition $(\beta=-.59, p<.01)$. Avoidance was not associated with attachment-related ES scores in the high-cognitive load condition $(\beta=-.02)$, however. As depicted in Figure 2, for individuals not currently in a relationship, avoidance was not significantly associated with attachment-related ES scores in either the low- or high-cognitive load conditions ( $\beta s \leq|.09|$, $p \mathrm{~s}>.56$ ). (Note that an ES score of 0 reflects no interference compared to neutral words.) Thus, reductions in ES interference were observed among highly avoidant individuals, for both positive and negative attachmentrelated words, but only among those currently in a romantic relationship and only under conditions of low cognitive load.

The same regression analysis predicting ES scores for the emotional words revealed only a main effect of $\operatorname{cog}$ nitive load condition $(\beta=.16, p<.05)$. ES scores were higher in the high-load condition $(M=12.93, S D=$ 41.67) than in the low-load condition $(M=.96, S D=$ 37.72). Thus, the effects of avoidance and relationship status on ES performance were specific to words reflecting attachment-related constructs.

\section{DISCUSSION}

The present findings indicate that avoidant individuals can inhibit attention to negative and positive attachmentrelated material, which results in a reduction of the ES effect. Avoidance was unrelated to ES scores for positive and negative emotional (nonattachment-related) words, however, suggesting that avoidant individuals' regulatory skills are most evident when processing material that could elicit attachment-related fears and concerns.

Importantly, avoidant attentional biases were observed only among participants who were currently in a romantic relationship; for participants who were not in a relationship, avoidance was unrelated to ES interference for attachment-related material. Perhaps being in a relationship activates avoidant defensive strategies, making avoidant individuals more sensitive to the effects of attachment-related stimuli and more likely to limit attention to such stimuli. Those in a relationship also might 
TABLE 2: Correlations Among Study Variables

\begin{tabular}{|c|c|c|c|c|c|c|c|c|c|c|}
\hline & 1 & 2 & 3 & 4 & 5 & 6 & 7 & 8 & 9 & 10 \\
\hline \multicolumn{11}{|l|}{ Gender } \\
\hline Cognitive load condition & -.01 & & & & & & & & & \\
\hline Block order & .04 & -.01 & & & & & & & & \\
\hline Relationship status & .07 & .04 & .07 & & & & & & & \\
\hline Avoidance & -.06 & -.06 & -.10 & $-.31 * *$ & & & & & & \\
\hline Anxiety & -.03 & -.05 & $-.20 * *$ & $-.15^{*}$ & $.42 * *$ & & & & & \\
\hline RT: Attachment words & -.14 & .10 & -.01 & -.12 & .13 & .12 & & & & \\
\hline RT: Emotional words & $-.15 *$ & $.18^{*}$ & .06 & -.13 & .14 & .12 & $.81 * *$ & & & \\
\hline RT: Neutral words & $-.16^{*}$ & $.14 *$ & .04 & -.10 & $.17^{*}$ & .11 & $.90 * *$ & $.92 * *$ & & \\
\hline Attachment ES score & .04 & -.09 & -.12 & -.05 & -.08 & -.08 & $.26 * *$ & $-.24 * *$ & $-.20 * *$ & \\
\hline Emotional ES score & -.03 & $.16^{*}$ & .07 & -.11 & -.02 & -.02 & .02 & $.44 * *$ & .07 & -.14 \\
\hline
\end{tabular}

NOTE: Gender: 0 = male, $1=$ female ; cognitive load condition: $0=$ low load, $1=$ high load; block order: $0=$ attachment-related words first, $1=$ emotional words first; relationship status: $0=$ not currently in a romantic relationship, $1=$ currently in a romantic relationship; emotional Stroop (ES) scores were computed by subtracting average neutral reaction times (RTs) from the average RT for each of the other word types. Larger scores reflect greater interference compared to neutral words. $N=189$.

$* p \leq .05 . * p<.01$.

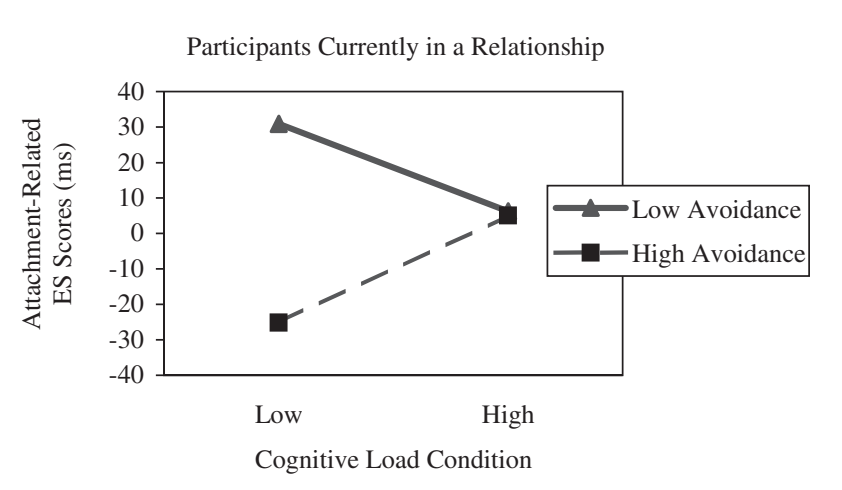

Figure 1 The relation between avoidance and emotional Stroop (ES) scores for attachment-related words among participants currently in a relationship.

NOTE: Regression lines are plotted separately for the low- and high-cognitive load conditions, at 1 standard deviation above and below the means of avoidance. Larger ES scores indicate greater interference relative to neutral words.

have more experience and proficiency in using defensive strategies to regulate emotion. For individuals who are not in a relationship, threats to that relationship (e.g., divorce) or to self-sufficiency (e.g., intimacy) may be less salient and less relevant to one's current concerns.

It is possible that by limiting attachment-related distress, these defensive strategies serve a relationship-maintenance function, allowing avoidant individuals to be in close relationships despite the discomfort they associate with closeness and intimacy. Along these lines, Main (1981) argued that avoidant infants' tendencies to suppress emotional displays and avoid proximity in stressful situations may be the most adaptive strategy for maintaining proximity to a caregiver who is uncomfortable with emotion. Although further research is necessary, findings from the present study lend support to the idea that

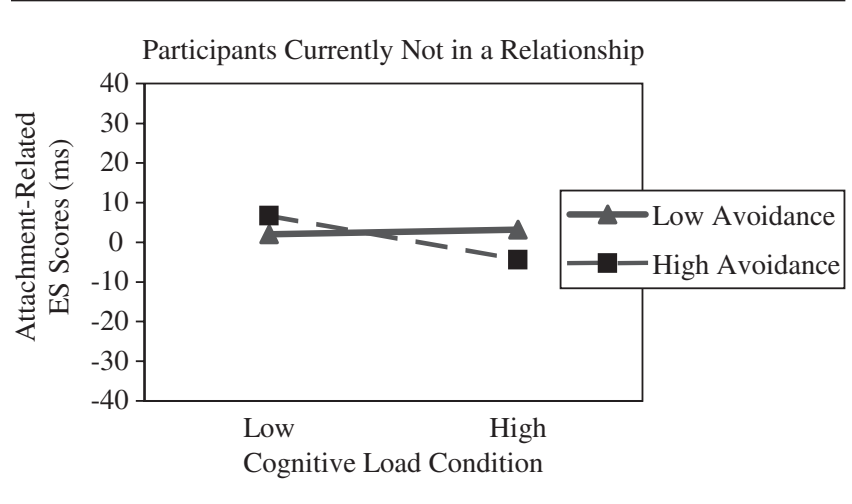

Figure 2 The relation between avoidance and emotional Stroop (ES) scores for attachment-related words among participants not currently in a relationship.

NOTE: Regression lines are plotted separately for the low- and high-cognitive load conditions, at 1 standard deviation above and below the means of avoidance. Larger ES scores indicate greater interference relative to neutral words.

avoidance in adulthood may serve a similar relationshipmaintenance function.

We also found that avoidant attentional biases were attenuated in the high-cognitive load condition. If the reduction of interference observed among avoidant individuals truly reflected lack of concern with attachmentrelated stimuli, imposition of a cognitive load should not have affected their performance; that is, completing the ES task while under a cognitive load should have increased reaction times for all stimuli (the zero-order correlations presented in Table 2 support this idea) without impairing avoidant individuals' ability to respond more quickly to attachment-related than to neutral material. Conversely, if reduced interference reflects active attempts to inhibit attention to (or suppress the meaning of) attachment-related material, then the imposition of a 
secondary task should make such inhibition more difficult. Our findings are consistent with this latter possibility, suggesting that at least among individuals in a relationship, avoidant-processing biases result from the effortful inhibition of attachment-related material.

In general, such inhibition or suppression of emotion has been associated with negative consequences for mental and physical health (e.g., Gross \& John, 2003; Mauss \& Gross, 2004). Insofar as avoidant individuals' lack of attention to attachment-related material similarly reflects an effortful inhibitory strategy, as suggested by the present findings, such biases may put avoidant individuals at risk for later adverse consequences. Prior research has linked avoidance with concurrent mental health problems (e.g., Mikulincer, Horesh, Eliati, \& Kotler, 1999; Rholes, Simpson, \& Friedman, 2006) and with increases in such problems over time (Berant et al., 2001; Berant, Mikulincer, \& Florian, 2003). However, mediators of the avoidancedistress relationship remain elusive (but see Berant et al., 2001, 2003, for an assessment of perceived coping abilities). The attentional biases identified in the present study may be one mechanism through which avoidance contributes to long-term changes in mental and physical health.

Of note, studies of perceptual bias provide some evidence for hypervigilance to emotional stimuli among avoidant individuals (Maier et al., 2005; Niedenthal, Brauer, Robin, \& Innes-Ker, 2002; but see Fraley et al., 2006). These studies suggest that avoidant adults have lower perceptual thresholds for (i.e., are quicker to recognize) emotional pictures, including facial expressions, social interactions, and animals. At first glance, these findings appear inconsistent with those presented here, indicating that avoidant individuals are less attentive to attachment-related material. However, Niedenthal et al. (2002) argue that perceptual biases operate at very early stages of information processing, allowing avoidant individuals to quickly identify potential sources of threat that, given additional time and resources, can subsequently be avoided. According to this proposal, avoidant defensive strategies are the product of a secondary, more effortful strategy occurring later in the information-processing sequence (see also SonnbyBorgström \& Jonsson, 2004). Our finding that avoidant attentional biases were disrupted when a cognitive load was imposed is consistent with this idea. Thus, perhaps avoidant individuals can identify potential sources of threat very quickly at a perceptual level, which then allows them to inhibit attention to those threats at later stages of processing. Further research is clearly needed, however, to fully test Niedenthal et al.'s proposal, ideally using tasks that are sensitive enough to capture both early and late cognitive processes.
Most research using the ES paradigm suggests that trait and clinically anxious individuals are overly attentive to emotional information, particularly information that reflects their "current concerns." However, in the present study, attachment-related anxiety did not predict ES scores for emotional or attachment-related words, either directly or in combination with attachment avoidance. Perhaps the attachment-related stimuli used in the present study were not particularly salient for individuals with high levels of attachment anxiety, or perhaps anxiously attached individuals are hypervigilant to attachment-related stimuli but other cognitive processes (e.g., semantic associations, rumination) counteract any effects of hypervigilance on colornaming latencies. Nonetheless, the present (null) findings regarding attachment anxiety are consistent with past research on short- and long-term memory, suggesting that anxious individuals are no better or worse at recalling attachment-related information and experiences (e.g., Edelstein, 2006; Edelstein et al., 2005; Fraley et al., 2000). Determining the conditions under which attachment anxiety may facilitate or impair attention and memory, as well as identifying the mechanisms underlying these effects, are important avenues for future research.

Finally, despite widespread use of the ES task as a measure of emotional processing biases (e.g., Williams et al., 1996), it should nevertheless be noted that the source of bias in this task remains somewhat controversial (e.g., Algom, Chajut, \& Lev, 2004). Some have argued, for instance, that differences in response latencies to emotional versus neutral words reflect not only attentional differences but also differences in the frequency with which groups of individuals use a particular word or lexical properties of the words (e.g., Larsen et al., 2006). In the present study, important lexical characteristics of the words (e.g., frequency, length) were equated across word type, making it less likely that such differences are responsible for the effects observed here. However, we cannot rule out the possibility that avoidant individuals showed less interference for attachment-related words not because they were inhibiting attention to them (or suppressing their semantic meaning) but simply because they are less familiar with these words or less likely to use them. Although our findings are consistent with prior research that has used more indirect measures of attention (e.g., Edelstein, 2006), lexical tasks such as the ES make it difficult to tease apart these different explanations. Thus, future research on avoidant-processing biases should include other measures of attention (e.g., attentional probe tasks; MacLeod, Mathews, \& Tata, 1986), ideally incorporating pictorial or other nonlexical stimuli (Gillath et al., 2007). 
In conclusion, our findings demonstrate that avoidant individuals can inhibit attention to attachment-related stimuli. Avoidant-processing biases were evident for both positive and negative attachment-related words but not for emotional words less directly related to attachment, emphasizing both the specificity of these biases and avoidant individuals' ability to quickly differentiate among these types of words. Yet our findings also demonstrate that there are at least two boundary conditions on avoidant attentional biases: First, such biases were evident only among avoidant individuals who were currently in a romantic relationship, providing some initial evidence that being in a relationship makes threats to that relationship more salient and may activate avoidant defensive strategies. Second, we found that avoidant attentional biases were attenuated when a secondary task was imposed, suggesting that this defensive strategy involves the effortful inhibition of attachment-related material. Whether reliance on such inhibitory processes has adverse consequences for emotional and physical health warrants further investigation.

\section{APPENDIX \\ SAMPLE WORDS USED IN EMOTIONAL STROOP TASK}

\begin{tabular}{|c|c|c|c|c|}
\hline Neutral & Positive Emotional & Negative Emotional & Positive Attachment & Negative Attachment \\
\hline Average & Beauty & Cruel & Adore & Abandon \\
\hline Banner & Charity & Curse & Affection & Alone \\
\hline Border & Heaven & Disease & Caring & Despair \\
\hline Combine & Justice & Disturb & Comfort & Divorce \\
\hline Divide & Liberty & Mistake & Depend & Hurt \\
\hline Exact & Paradise & Nasty & Embrace & Insecure \\
\hline Middle & Pure & Tired & Intimate & Lonely \\
\hline Notice & Smart & Ugly & Loving & Loss \\
\hline Permit & Wealth & Violence & Support & Reject \\
\hline Quantity & Wisdom & Wicked & Trust & Sorrow \\
\hline
\end{tabular}

\section{NOTES}

1. Although avoidance and anxiety are typically conceptualized as independent dimensions, it is not uncommon for the two Experiences in Close Relationships Inventory (ECR) subscales to be positively correlated. This correlation could reflect the large proportion of secure and/or fearful individuals in the present study (i.e., individuals with low scores on both dimensions or high scores on both dimensions, respectively), although inspection of the means in Table 1 suggests that the sample is relatively secure.

2. We also computed residualized emotional Stroop (ES) scores by saving the standardized residuals from regression analyses predicting reaction times (RTs) for each of the four emotional word types from neutral RTs. These residualized scores were strongly correlated with the difference scores used in the present analyses $(r s>.98)$ and yielded highly similar results in all analyses presented here.

3 . The repeated-measures analysis also yielded a significant fourway interaction between attachment anxiety, emotional valence, relationship status, and cognitive load, $F(1,173)=6.42, p<.05$. Deconstructing this interaction in the manner described earlier indicated that among individuals in a relationship, attachment anxiety was positively associated with ES scores for negative words (collapsed across word type) in the high-cognitive load condition, $\beta=.43$, $p<$ .05 . Among individuals not in a relationship, attachment anxiety was positively associated with negative ES scores in the low-cognitive load condition, $\beta=.35, p<.05$. Given that our focus was on avoidance, and because we did not have a theoretical basis for predicting this four-way interaction, this effect is not discussed further.

\section{REFERENCES}

Aiken, L. S., \& West, S. G. (1991). Multiple regression: Testing and interpreting interactions. Newbury Park, CA: Sage.

Algom, D., Chajut, E., \& Lev, S. (2004). A rational look at the emotional Stroop phenomenon: A generic slowdown, not a Stroop effect. Journal of Experimental Psychology: General, 133, 323-338.

Bahrick, H. P. (2000). Long-term maintenance of knowledge. In E. Tulving \& F. I. M. Craik (Eds.), The Oxford handbook of memory (pp. 347-362). New York: Oxford University Press.

Bayliss, D. M., Jerrold, C., Gunn, D. M., \& Baddeley, A. D. (2003). The complexities of complex span: Explaining individual differences in working memory in children and adults. Journal of Experimental Psychology: General, 132, 71-92.

Berant, E., Mikulincer, M., \& Florian, V. (2001). Attachment style and mental health: A 1-year follow-up study of mothers of infants with congenital heart disease. Personality and Social Psychology Bulletin, 27, 956-968.

Berant, E., Mikulincer, M., \& Florian, V. (2003). Marital satisfaction among mothers of infants with congenital heart disease: The contribution of illness severity, attachment style, and the coping process. Anxiety, Stress and Coping, 16, 397-415.

Bowlby, J. (1980). Attachment and loss, Vol. III: Loss, sadness and depression. New York: Basic Books.

Bowlby, J. (1987). Defensive processes in the light of attachment theory. In J. L. Sacksteder, D. P. Schwartz, \& Y. Akabane (Eds.), Attachment and the therapeutic process: Essays in honor of Otto Allen Will, Jr. (pp. 63-79). Madison, CT: International Universities Press. 
Bradley, B. P., Mogg, K., Falla, S. J., \& Hamilton, L. R. (1998). Attentional bias for threatening facial expressions in anxiety: Manipulation of stimulus duration. Cognition and Emotion, 12, 737-753.

Bradley, M. M., Greenwald, M. K., Petry, M. C., \& Lang, P. J. (1992). Remembering pictures: Pleasure and arousal in memory. Journal of Experimental Psychology: Learning, Memory, and Cognition, 18, 379-390.

Brennan, K. A., Clark, C. L., \& Shaver, P. R. (1998). Self-report measurement of adult attachment: An integrative overview. In J. A. Simpson \& W. S. Rholes (Eds.), Attachment theory and close relationships (pp. 46-76). New York: Guilford.

Broomfield, N. M., \& Turpin, G. (2005). Covert and overt attention in trait anxiety: A cognitive psychophysiological analysis. Biological Psychology, 68, 179-200.

Christopher, C. (2001). SuperLab Pro (Version 2.01) [Computer software]. San Pedro, CA: Cedrus Corporation.

Dolcos, F., LaBar, K. S., \& Cabeza, R. (2005). Remembering one year later: Role of the amygdala and the medial temporal lobe memory system in retrieving emotional memories. Proceedings of the National Academy of Sciences, 102, 2626-2631.

Edelstein, R. S. (2006). Attachment and emotional memory: Investigating the source and extent of avoidant memory deficits. Emotion, 6, 340-345.

Edelstein, R. S., Alexander, K. W., Shaver, P. R., Schaaf, J. M., Quas, J. A., Lovas, G. S., et al. (2004). Adult attachment style and parental responsiveness during a stressful event. Attachment and Human Development, 6, 31-52.

Edelstein, R. S., Ghetti, S., Quas, J. A., Goodman, G. S., Alexander, K. W., Redlich, A. D., et al. (2005). Individual differences in emotional memory: Adult attachment and long-term memory for child sexual abuse. Personality and Social Psychology Bulletin, 31, 1537-1548.

Edelstein, R. S., \& Shaver, P. R. (2004). Avoidant attachment: Exploration of an oxymoron. In D. Mashek \& A. Aron (Eds.), Handbook of closeness and intimacy (pp. 397-412). Mahwah, NJ: Lawrence Erlbaum.

Engle, R. W. (2002). Working memory capacity as executive attention. Current Directions in Psychological Science, 11, 19-23.

Eysenck, M. W. (1992). Anxiety: The cognitive perspective. Hove, UK: Lawrence Erlbaum.

Eysenck, M. W. (1997). Anxiety and cognition: A unified theory. Hove, UK: Psychology Press.

Fox, E. (1993). Allocation of visual attention and anxiety. Cognition and Emotion, 7, 207-215.

Fox, E., Russo, R., Bowles, R., \& Dutton, K. (2001). Do threatening stimuli draw or hold visual attention in subclinical anxiety? Journal of Experimental Psychology: General, 130, 681-700.

Fraley, R. C., Davis, K. E., \& Shaver, P. R. (1998). Dismissing avoidance and the defensive organization of emotion, cognition, and behavior. In J. A. Simpson \& W. S. Rholes (Eds.), Attachment theory and close relationships (pp. 249-279). New York: Guilford.

Fraley, R. C., Garner, J. P., \& Shaver, P. R. (2000). Adult attachment and the defensive regulation of attention and memory: Examining the role of preemptive and postemptive defensive processes. Journal of Personality and Social Psychology, 79, 816-826.

Fraley, R. C., Niedenthal, P. M., Marks, M., Brumbaugh, C., \& Vicary, A. (2006). Adult attachment and the perception of emotional expressions: Probing the hyperactivating strategies underlying anxious attachment. Journal of Personality, 74, 1163-1190.

Fraley, R. C., \& Shaver, P. R. (1997). Adult attachment and the suppression of unwanted thoughts. Journal of Personality and Social Psychology, 73, 1080-1091.

Fraley, R. C., \& Waller, N. G. (1998). Adult attachment patterns: A test of the typological model. In J. A. Simpson \& W. S. Rholes (Eds.), Attachment theory and close relationships (pp. 77-114). New York: Guilford.

Gillath, O., Bunge, S. A., Shaver P. R., Wendelken, C., \& Mikulincer, M. (2005). Attachment-style differences in the ability to suppress negative thoughts: Exploring the neural correlates. Neuroimage (Special Issue: Social Cognitive Neuroscience), 28, 835-847.

Gillath, O., Giesbrecht, B., \& Shaver, P. R. (2007). Attachment, attention, and cognitive control: The role attention and eye movements play in attachment style. Unpublished manuscript.
Gillath, O., Mikulincer, M., Fitzsimons, G. M., Shaver, P. R., Schachner, D. A., \& Bargh, J. A. (2006). Automatic activation of attachment-related goals. Personality and Social Psychology Bulletin, 32, 1375-1388.

Gross, J. J., \& John, O. P. (2003). Individual differences in two emotion regulation processes: Implications for affect, relationships, and well-being. Journal of Personality and Social Psychology, 85, 348-362.

Hamann, S., \& Canli, T. (2004). Individual differences in emotion processing. Current Opinion in Neurobiology, 12, 233-238.

Hamann, S. B., Ely, T. D., Hoffman, J. M., \& Kilts, C. D. (2002). Ecstasy and agony: Activation of the human amygdala in positive and negative emotion. Psychological Science, 13, 135-141.

Kaspi, S. P., McNally, R. J., \& Amir, N. (1995). Cognitive processing of emotional information in posttraumatic stress disorder. Cognitive Therapy and Research, 19, 433-444.

Kelly, A. E., \& Kahn, J. H. (1994). Effects of suppression of personal intrusive thoughts. Journal of Personality and Social Psychology, 66, 998-1006.

Kensinger, E. A., \& Corkin, S. (2003). Effect of negative emotional content on working memory and long-term memory. Emotion, 3, 378-393.

Kirsh, S., \& Cassidy, J. (1997). Preschoolers' attention to and memory for attachment-relevant information. Child Development, 68, $1143-1153$.

Koven, N. S., Heller, W., Banich, M. T., \& Miller, G. A. (2003). Relationships of distinct affective dimensions to performance on an emotional Stroop task. Cognitive Therapy and Research, 27, 671-680.

Lang, P. J., Bradley, M. M., \& Cuthbert, B. N. (1997). Motivated attention: Affect, activation, and action. In P. J. Lang, R. F. Simons, \& M. T. Balaban (Eds.), Attention and orienting: Sensory and motivational processes (pp. 97-135). Mahwah, NJ: Lawrence Erlbaum.

Lang, P. J., Greenwald, M. K., Bradley, M. M., \& Hamm, A. O. (1993). Looking at pictures: Affective, facial, visceral, and behavioral reactions. Psychophysiology, 30, 261-273.

Larsen, R. J., Mercer, K. A., \& Balota, D. A. (2006). Lexical characteristics of words used in emotional Stroop experiments. Emotion, 6, 62-72.

MacKay, D. G., Shafto, M., Taylor, J. K., Marian, D. E., Abrams, L. \& Dyer, J. R. (2004). Relations between emotion, memory, and attention: Evidence from taboo Stroop, lexical decision, and immediate memory tasks. Memory \& Cognition, 32, 474-488.

MacLeod, C., Mathews, A., \& Tata, P. (1986). Attentional bias in emotional disorders. Journal of Abnormal Psychology, 95, 15-20.

Maier, M. A., Bernier, A., Pekrun, R., Zimmerman, P., Strasser, K., \& Grossmann, K. E. (2005). Attachment state of mind and perceptual processing of emotional stimuli. Attachment and Human Development, 7, 67-81.

Main, M. (1981). Avoidance in the service of attachment: A working paper. In K. Immelmann, G. Barlow, L. Petrinovich, \& M. Main (Eds.), Behavioral development: The Bielefeld interdisciplinary project (pp. 651-693). New York: Cambridge University Press.

Mauss, I. B., \& Gross, J. J. (2004). Emotion suppression and cardiovascular disease: Is hiding feelings bad for your heart? In L. R. Temoshok, I. Nyklicek, \& A. Vingerhoets (Eds.), Emotional expression and health: Advances in theory, assessment, and clinical applications (pp. 62-81). New York: Brunner-Routledge.

McKenna, F. P., \& Sharma, D. (1995). Intrusive cognitions: An investigation of the emotional Stroop task. Journal of Experimental Psychology: Learning, Memory, and Cognition, 21, 1595-1607.

Mikulincer, M., Birnbaum, G., Woddis, D., \& Nachmias, O. (2000). Stress and accessibility of proximity-related thoughts: Exploring the normative and intraindividual components of attachment theory. Journal of Personality and Social Psychology, 78, 509-523.

Mikulincer, M., Dolev, T., \& Shaver, P. R. (2004). Attachmentrelated strategies during thought-suppression: Ironic rebounds and vulnerable self -representations. Journal of Personality and Social Psychology, 87, 940-956.

Mikulincer, M., Florian, V., \& Weller, A. (1993). Attachment styles, coping strategies, and posttraumatic psychological distress: The 
impact of the Gulf War in Israel. Journal of Personality and Social Psychology, 64, 817-826.

Mikulincer, M., Gillath, O., \& Shaver, P. R. (2002). Activation of the attachment system in adulthood: Threat-related primes increase the accessibility of mental representations of attachment figures. Journal of Personality and Social Psychology, 83, 881-895.

Mikulincer, M., Horesh, N., Eliati, I., \& Kotler, M. (1999). The association between adult attachment style and mental health in extreme life-endangering conditions. Personality and Individual Differences, 27, 831-842.

Mikulincer, M., \& Orbach, I. (1995). Attachment styles and repressive defensiveness: The accessibility and architecture of affective memories. Journal of Personality and Social Psychology, 68, 917-925.

Mikulincer, M., Shaver, P. R., \& Pereg, D. (2003). Attachment theory and affect regulation: The dynamics, development and cognitive consequences of attachment-related strategies. Motivation and Emotion, 27, 77-102.

Miyake, A., \& Shah, P. (1999). Toward unified theories of working memory: Emerging general consensus, unresolved theoretical issues, and future research directions. In A. Miyake \& P. Shah (Eds.), Models of working memory: Mechanisms of active maintenance and executive control (pp. 442-481). Cambridge, UK: Cambridge University Press.

Mogg, K., Bradley, B. P., Dixon, C., Fisher, S., Twelftree, H., \& McWilliams, A. (2000). Trait anxiety, defensiveness and selective processing of threat: An investigation using two measures of attentional bias. Personality and Individual Differences, 28, 1063-1077.

Nelson, D. L., McEvoy, C. L., \& Schreiber, T. A. (1998). The University of South Florida word association, rhyme, and word fragment norms. Retrieved from http://www.usf.edu/FreeAssociation/

Newman, L. S., \& McKinney, L. C. (2002). Repressive coping and threat-avoidance: An idiographic Stroop study. Personality and Social Psychology Bulletin, 28, 409-422.

Niedenthal, P. M., Brauer, M., Robin, L., \& Innes-Ker, A. H. (2002). Adult attachment and the perception of facial expression of emotion. Journal of Personality and Social Psychology, 82, 419-433.

Ochsner, K. N. (2000). Are affective events richly recollected or simply familiar? The experience and process of recognizing feelings past. Journal of Experimental Psychology: General, 129, 242-261.
Ohman, A., Flykt, A., \& Esteves, F. (2001). Emotion drives attention: Detecting the snake in the grass. Journal of Experimental Psychology: General, 130, 466-478.

Pratto, F., \& John, O. P. (1991). Automatic vigilance: The attentiongrabbing power of negative social information. Journal of Personality and Social Psychology, 61, 380-391.

Ratcliff, R. (1993). Methods for dealing with reaction-time outliers. Psychological Bulletin, 114, 510-532.

Rholes, W. S., Simpson, J. A., \& Friedman, M. (2006). Avoidant attachment and the experience of parenting. Personality and Social Psychology Bulletin, 32, 275-285.

Segerstrom, S. C. (2001). Optimism and attentional bias for positive and negative stimuli. Personality and Social Psychology Bulletin, $27,1334-1343$.

Sonnby-Borgström, M., \& Jonsson, P. (2004). Dismissing-avoidant pattern of attachment and mimicry reactions at different levels of processing. Scandinavian Journal of Psychology, 45, 103-113.

van Emmichoven, I. A., van IJzendoorn, M. H., de Ruiter, C., \& Brosschot, J. F. (2003). Selective processing of threatening information: Effects of attachment representation and anxiety disorder on attention and memory. Development and Psychopathology, 15, 219-237.

Weiss, R. S. (1982). Attachment in adult life. In C. M. Parkes \& J. Stevenson-Hinde (Eds.), The place of attachment in human behavior (pp. 171-184). New York: Basic Books.

Williams, J. M. G., Mathews, A., \& MacLeod, C. (1996). The emotional Stroop task and psychopathology. Psychological Bulletin, 120, 3-24.

Wilson, M. D. (1988). The MRC psycholinguistic database: Machine readable dictionary (Version 2). Behavior Research Methods, Instruments and Computers, 20, 6-11. Retrieved from http://www.psy .uwa.edu.au/mrcdatabase/uwa_mrc.htm

Received August 10, 2006

Revision accepted July 13, 2007 